Article

\title{
Science Walden: Exploring the Convergence of Environmental Technologies with Design and Art
}

\author{
Hyun-Kyung Lee ${ }^{1, *}$, Kyung Hwa Cho ${ }^{2}$, Changsoo Lee ${ }^{2}$, Jaeweon Cho ${ }^{2}$, Huiyuhl $\mathrm{Yi}^{1}$, \\ Yongwon Seo ${ }^{2}$, Gi-Hyoug Cho ${ }^{2}$, Young-Nam Kwon ${ }^{2}$, Changha Lee ${ }^{2}$ and Kyong-Mi Paek ${ }^{1}$ \\ 1 Division of General Studies, Ulsan National Institute of Science and Technology, UNIST-gil 50, \\ Ulsan 44919, Korea; huiyuhl@unist.ac.kr (H.Y.); kpaek@unist.ac.kr (K.-M.P.) \\ 2 School of Urban and Environmental Engineering, Ulsan National Institute of Science and Technology, \\ UNIST-gil 50, Ulsan 44919, Korea; khcho@unist.ac.kr (K.H.C.); cslee@unist.ac.kr (C.L.); \\ jaeweoncho@unist.ac.kr (J.C.); ywseo@unist.ac.kr (Y.S.); gicho@unist.ac.kr (G.-H.C.); \\ kwonyn@unist.ac.kr (Y.-N.K.); clee@unist.ac.kr (C.L.) \\ * Correspondence: hlee@unist.ac.kr; Tel.: +82-52-217-2032 \\ Academic Editor: Vincenzo Torretta \\ Received: 10 October 2016; Accepted: 23 December 2016; Published: 28 December 2016
}

\begin{abstract}
Science Walden, which is inspired by two prominent literary works, namely, Walden by Henry David Thoreau (1817-1862) and Walden Two by Burrhus Frederic Skinner (1904-1990), is aimed at establishing a community that embodies humanistic values while embracing scientific advancement to produce renewable energy and water sources. This study attempts to capitalize on feces standard money (FSM) and artistic collaboration between scientists and artists as a means of achieving the forms of life depicted in Walden and Walden Two. On our campus, we designed and built a pavilion that serves as a laboratory where scientific advantages, design, and art are merged. In the pavilion, feces are processed in reactors and facilities for sustainable energy production, and rainwater is harvested and treated for use in daily life. Our application of design and art contributes to easing interaction between the general public and scientists because it visualizes an ambiguous theory and concretizes it into an understandable image.
\end{abstract}

Keywords: feces standard money (FSM); collaboration of science \& art; sustainable energy production

\section{Introduction}

\subsection{Why "Science Walden?"}

The term "Science Walden" is the product of the dialectical development of thought on two eminent literary works: Walden by Henry David Thoreau (1817-1862) and Walden Two by Burrhus Frederic Skinner (1904-1990). The life of Thoreau portrayed in Walden is an isolated one. He keeps himself away from other human communities, leading a genuinely self-sustaining life in his cabin at Walden Pond [1]. His minimalist lifestyle stems from a distrust of capitalism, which causes unbridled competition and expands vulgar materialism. Meanwhile, Walden Two depicts an agricultural commune where citizens lead pleasant and peaceful lives [2]. They seem to represent an exemplar of collective life: the inhabitants share labor, enjoy various kinds of recreation, and pursue their own choices of artistic projects in a crime-free environment. However, those who live in this community turn out to be carefully controlled to conduct themselves in certain ways by behavioral engineers. For example, they are conditioned to be cooperative and gentle and to desire only what they can have or choose.

Influenced by the forms of life in Walden and Walden Two, Science Walden is aimed at establishing a community that embodies humanistic values while positively embracing the technological advancement of modern civilization. It accords with Thoreau in that a nature-oriented life is pursued, 
but it deviates from his orientation in that it does not shun scientific accomplishments. Science Walden, instead, considerably emphasizes the use of cutting-edge technologies in constructing an infrastructure for an environment-friendly life. The community of Science Walden is also based on the systematic and well-organized managerial principles described in Walden Two but does not infringe on the autonomy of its members. Voluntary participation in social events and activities is encouraged. These practices embody a place of convergence where human beings engage with science and technology. In sum, our project inherits the philosophical legacies underlying the two literary works and establishes a pragmatic community, with the benefit of scientific improvement as a backdrop.

\subsection{Sa-Wol-Dang Pavilion}

In the project, two ways of connecting scientific technologies and implementation in a community were attempted: the use of feces standard money (FSM; refer to edge.org/response-detail/26660) and artistic collaboration between scientists and artists. FSM is not a substitute for, but a complement to, the currency used in present economic and social systems. We believe that arts, or liberal arts, can ignite imagination and provide courage as we map out a community through scientific concepts and ideas. To experience all of the target endeavors, we designed and built a pavilion that serves as a laboratory where scientists and artists study the goals of Science Walden together (Figure 1). The pavilion is called Sa-Wol-Dang, which is Chinese for "a place to think about what is beyond".
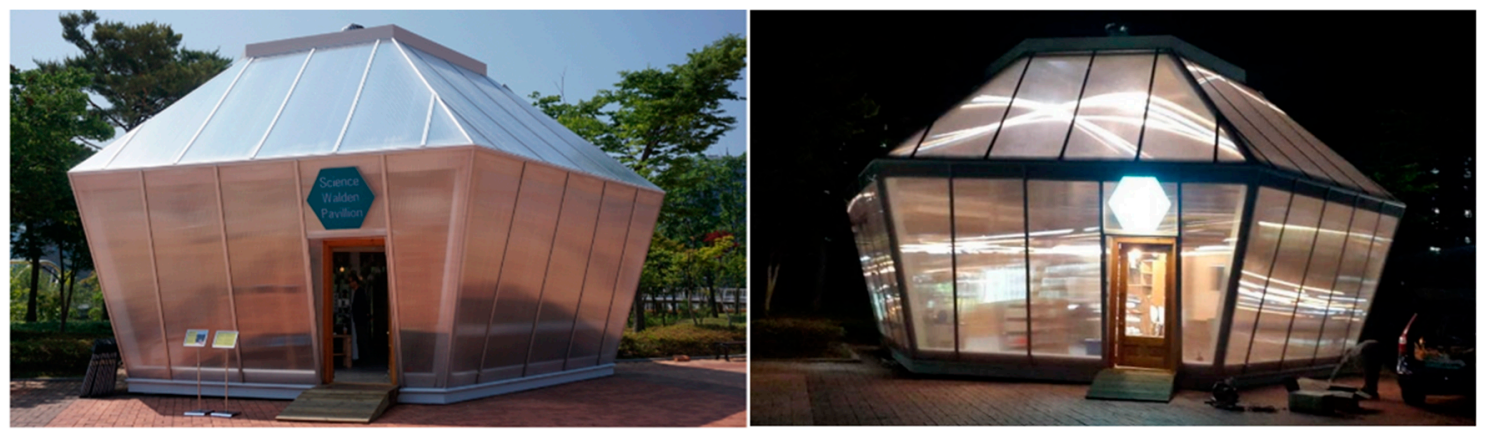

Figure 1. Sa-Wol-Dang at the UNIST campus.

\subsection{Objectives of the Study}

The Sa-Wol-Dang pavilion is designed to use space efficiently so that it accommodates as many research facilities as possible. The pavilion also helps advertise the participating activities of this project to the public, including the students of UNIST. While inviting people to experience the laboratory at the pavilion, we have met more than 2600 visitors since we opened it on 25 May 2016. We have listened to their opinions and comments thereafter. We believe that the feedback delivered to us, both positive and negative, help us build certain meanings and images so that we can adopt them to set up the future projects for our communities in both urban areas and rural villages, and see how to implement them. We noted that not many of the visitors used the non-flushing toilet, which reflected the public perception of our project concept. Though we did not interview the toilet users to obtain responses and comments, we could envision the next step of our project and corresponding activities based on the experience.

Even with relatively high wastewater treatment rate, we are experiencing many different kinds of environmental pollutions, including large-scale eutrophication, probably due to nitrogen and phosphorus contamination in rivers of Korea. Our society may have a public perception that environmental protection cannot accompany economic development or technological achievement. On the contrary, we believe that the preservation of environment may contribute to enhancing economic values. Our belief is evidenced by the realization of FSM: we can create value by producing energy from human feces (Figure 2). We have been attempting to increase the efficiency of the energy production 
while trying to change the public perception towards feces and their environmental/economic values. By redesigning our societal system to utilize the resources of recycled feces and bioenergy, and subsequently using the FSM as an alternative currency, we believe that we can renovate our current welfare system. In particular, the fact that everyone can provide more or less the same amount of feces as an energy source forms an underlying basis for the societal welfare system; everyone has the equal right to be benefitted by the communal energy management system as he or she is able to supply the sources of alternative forms of energy.
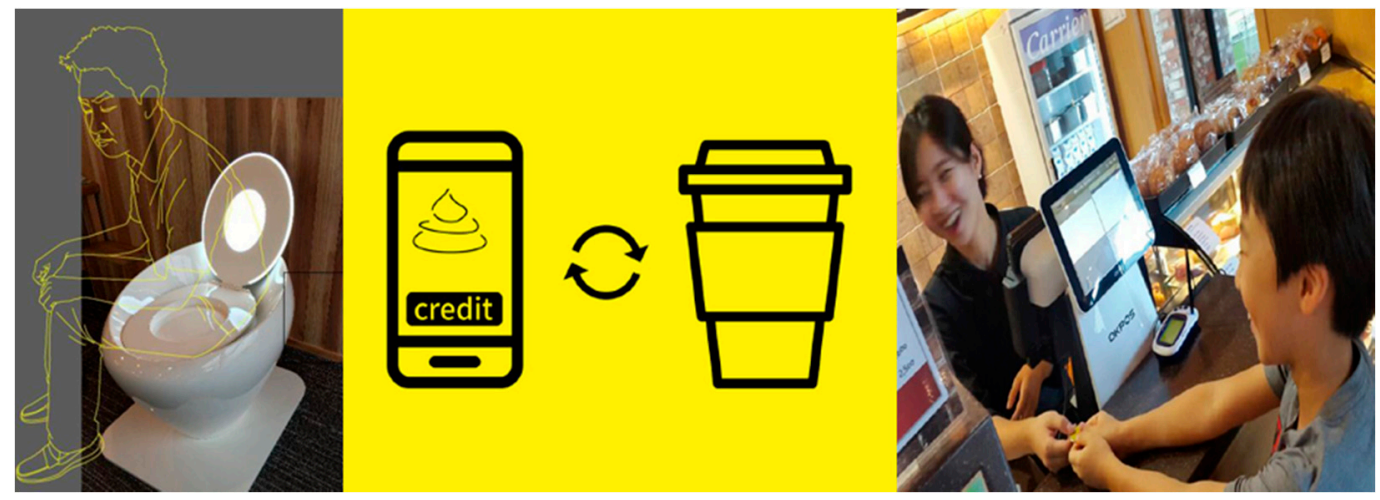

Figure 2. In the pavilion, there is a restroom where anyone from our campus or the nearby cities can come and experience defecation activities with waterless toilets. They can earn some credits from these activities and exchange them with a cup of coffee or other foods at the university cafe.

As a means of materializing the hardware that enables the FSM, we manufactured a prototype of a waterless toilet, which we dubbed as "the BeeVi toilet". The dried forms of feces generated by the BeeVi toilet are delivered into the anaerobic digestion bioreactor. The bioreactor produces biogas, from which we separate methane and carbon dioxide using either the hydrophobic membrane gas separation or semi-clathrate method. In order to illustrate that the energy thus produced may contribute to everyday life, we opened many interesting research events to perform eco-friendly activities. For instance, we once invited the university students to Sa-Wol-Dang pavilion where they cooked barley sprouts, which had been cultivated within the pavilion using the composts from feces, using the bioenergy generated by the separated methane in the pavilion lab as well. Water is another crucial source in producing the bioenergy. We harvest rainwater with the green roof and treat rainwater using the bi-metal and membrane processes. Artistic beauty permeates into the mid-products of our experimental procedures. Our participating researchers designed a future-oriented model of the BeeVi toilet (dummy) so that visitors can observe and give their suggestions for further improvements. The participating artists successfully visualized the bioenergy production rate from the digestion reactor in the form of the artistic works exhibited on the pavilion walls. The nature artists associated with our project created urban farming presentations where we can cultivate flowers and vegetables, such as barley, using the compost generated by our toilet system.

\section{Methods}

\subsection{Survey Study at UNIST}

We conducted structured interviews first randomly with 140 students enrolled at UNIST, who are the main residents of this community. We asked them three questions:

(1) What kind of buildings or a symbol do you want to have in your community? (2) Do you have any preferences for functions that this building might have? (3) What is your favorite building or creative structure? The responses were thematically analyzed. Although the interviewees majored in 
different types of engineering studies, similar themes emerged when categorizing their answers. Three themes were found:

a. Inspirational, symbolic, and Earth-friendly toilets and FSM system.

b. A place to know about what kind of science and technology is needed for this project.

c. An interactive artwork that stimulates.

Therefore, the students here at UNIST want a symbolic art installation as well as a place to know about science and art related to this project. We shared these findings from the community with the other members of our collaborative team in order to discuss the building directions for our research lab. Therefore, each lab decided to put some necessary system in the pavilion. The next section will offer a detailed description of each lab and how it functions in this project.

\subsection{Biogas Production from Feces}

In the pavilion, feces were subjected to a series of sustainable energy production processes, from anaerobic digestion and methane $\left(\mathrm{CH}_{4}\right)$ and carbon dioxide $\left(\mathrm{CO}_{2}\right)$ separation to green algae cultivation (Figure 3). The reactors and facilities for these processes were located within the pavilion and operated by supervisors who lead different research teams. We intended to use the produced $\mathrm{CH}_{4}$ for heating and both the $\mathrm{CH}_{4}$ and biodiesel generated from the green algae as fuel for a community bus. In this regard, the residents can use FSM as a means of payment.

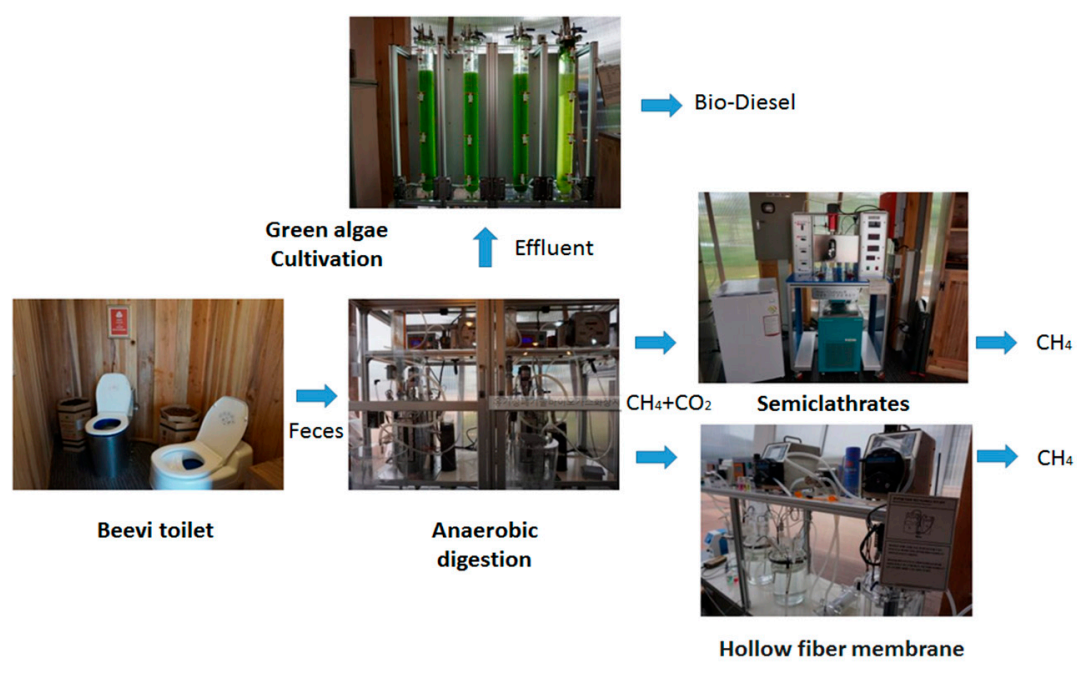

Figure 3. Reactors and facilities for sustainable energy production from feces.

We could have restricted the project to employing a non-flushing toilet, producing energy out of feces or manure, and recycling water to protect the environment and conserve energy and water. However, we envisioned a horizon that goes beyond these aims and accordingly designed Sa-Wol-Dang to motivate people to participate more sustainably in all of the activities proposed by Science Walden.

\subsubsection{Beevi Toilet}

The flushing toilet has been recognized as one of the greatest and worst inventions in scientific history from the perspectives of sanitation and the natural environment, respectively. Forgoing the use of flushing toilets means that, with the help of scientific developments, we can achieve something important that transcends what we can imagine. We hope to bring new value from the experience of not using flushing toilets and create a new horizon for our community. Accordingly, we placed three non-flushing toilets in the pavilion. 


\subsubsection{Biogas Production}

Anaerobic digestion has been widely applied to the treatment of high-strength organic wastes because it can stabilize pollution loads and produce renewable energy, in the form of biogas, simultaneously. Biogas consists of approximately $60 \% \mathrm{CH}_{4}$ and $40 \% \mathrm{CO}_{2}(v / v)$ and is attracting increasing attention as a promising energy source in the future. In Science Walden, feces and food waste (the major organic waste streams from human activities) are converted to biogas by anaerobic digestion, which forms the core unit of the energy recovery system in the Pavilion (Figure 3). Anaerobic digestion is a series of biological reactions involving diverse microbial groups with different metabolic functions and physiological characteristics [3]. Its performance, therefore, depends on the concerted activity of microorganisms involved, and is sensitive to changes in environmental conditions (e.g., temperature, $\mathrm{pH}$, oxidation reduction potential, salinity, and feed characteristics). Despite its high organic content, human feces has mostly been treated by aerobic processes due to hygiene and scalability issues. We examined feces (collected from the volunteer members of the project) and food waste (collected from a student cafeteria at UNIST campus) for biochemical methane potential (BMP) under mono- and co-digestion conditions. The BMP tests were performed for 28 days at $35^{\circ} \mathrm{C}$ in triplicate.

\subsection{3. $\mathrm{CO}_{2}$ Capture from Biogas Using Semiclathrates}

Many quaternary ammonium salts (QASs), such as tetra-n-butyl ammonium halides ( $\mathrm{F}, \mathrm{Cl}, \mathrm{Br}$ ), form semiclathrates with water at atmospheric pressure. In QAS semiclathrates, anions, such as $\mathrm{F}_{-}, \mathrm{Br}-$, and $\mathrm{Cl}-$, participate in building up host cage structures with water molecules, and tetra-n-butylammonium cations are incorporated into the partially broken large cages [4,5]. Since QAS semiclathrates have small empty cages, which are available for capturing small-sized gas molecules (Figure 4), they can be effectively used for gas storage and separation. QASs are also non-volatile and non-toxic and can thus be used repeatedly without loss in a semiclathrate-based separation process [6,7]. $\mathrm{CO}_{2}$ from biogas $\left(\mathrm{CH}_{4}+\mathrm{CO}_{2}\right)$ can be separated using semiclathrates because $\mathrm{CO}_{2}$ preferentially occupies the small cages of QAS semiclathrates, as shown in Figure 3. Such occupation is due to the higher thermodynamic stability of $\mathrm{CO}_{2}$ in semiclathrates than that of $\mathrm{CH}_{4}$. In this study, tetra-n-butylammonium chloride (TBAC) was used as a semiclathrate former to capture $\mathrm{CO}_{2}$ from biogas because among QASs, TBAC has the highest gas storage capacity and yields the highest equilibrium dissociation temperature [6,7].

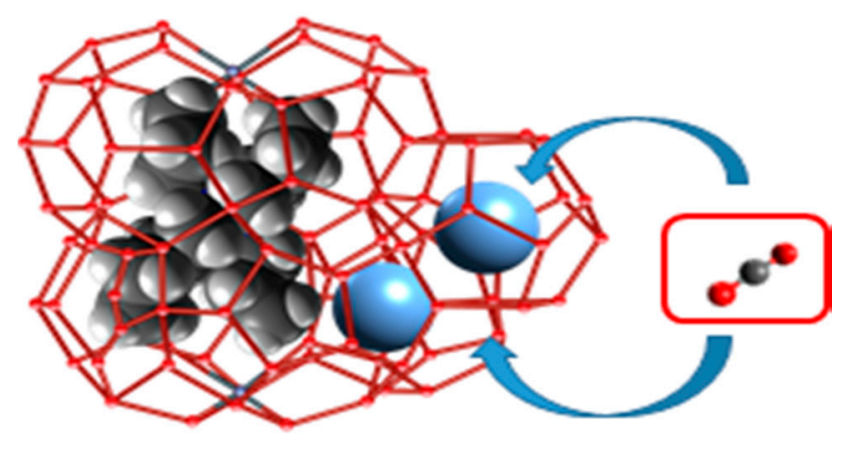

Figure 4. QAS semiclathrate.

\subsubsection{Purification Using a Membrane Technique}

In this study, $\mathrm{CO}_{2}$ separation in a digester was evaluated using a polypropylene hollow fiber membrane (Liqui-Cell @), which is a straw-like small tube with numerous tiny pores. The membrane is a selective physical separator of two phases and can pass one component more easily than others. Biogas flowed into the bore side (lumen) of the hollow fiber and was transported through the membrane pores. The $\mathrm{CO}_{2}$, having a higher Henry's constant, was selectively dissolved in the pure water in the shell side (outside). Thus, a high amount of soluble gas was removed from the reactor. 


\subsection{Rainwater Reduction and Treatment}

We prepared water necessary for the pavilion by harvesting rainwater from a green roof, after which the harvested water was filtered and disinfected (Figure 5). The gardens in the pavilion were designed together with an artist and a scientist, and we grow crops, such as barley, using the remaining compost converted from feces and the purified rainwater.

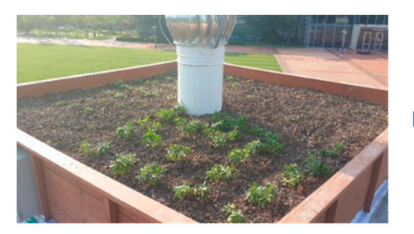

Greenroof

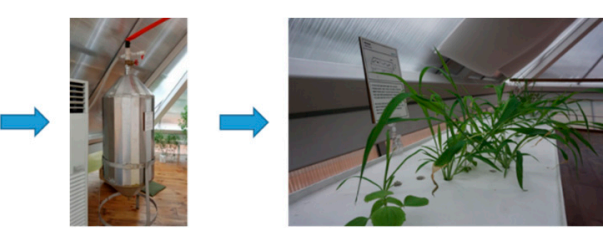

Cultivation
Storage

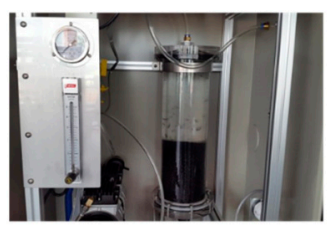

Integrated adsorption-

disinfection system

Figure 5. Rainwater harvesting and treatment system.

\subsubsection{Green Roof and Sand Filter System: Rainwater Reduction}

Under unexpected climate change, rapid and uncontrolled urbanization have resulted in severe flooding events and surface water pollution. Low-impact development (LID) has been proposed as a promising approach to reducing urban stormwater runoff and pollution [8,9]. LID aims to preserve the water cycle of a pre-development area by maximizing water infiltration into the soil layer and reducing surface runoff. A green roof is a building rooftop laid over permeable media and vegetation to control runoff volume and improve water quality, as well as reduce the occurrence of urban heat islands. It can be categorized into extensive or intensive types on the basis of the depth of a roof layer. The soil thickness of an intensive green roof is generally greater than $150 \mathrm{~mm}$, and that of an extensive green roof is less than $150 \mathrm{~mm}$. A green roof was placed on the center part of Sa-Wol-Dang's roof, covering approximately $50 \%$ of total area $(2 \mathrm{~m} \times 2 \mathrm{~m} \times 0.3 \mathrm{~m})$. The other $50 \%$ was considered as normal roofs. Effluent from a green roof is transported to a sand filter system, which improves the quality of the effluent.

\subsubsection{Integrated Adsorption-Disinfection System for Rainwater Treatment}

Rainwater harvesting has been considered a sustainable option of supplying water for potable and non-potable uses [10,11]. Rainwater treatment can be a simpler process than reclamation from wastewater because the former is characterized by better water quality. Using rainwater for different purposes (cleaning, laundry, toilet flushing, drinking, etc.) necessitates that potential contaminants, such as particles, organics, heavy metals, and pathogens, be properly removed to satisfy the water quality standard for each purpose. Large particles are relatively readily removed by sedimentation in a storage tank, and membrane filtration can be optional when microparticles are problematic. The removal of dissolved contaminants (e.g., dissolved organics and heavy metals) and the disinfection of pathogenic microorganisms are more challenging processes. An integrated adsorption-disinfection system was developed in this study to simultaneously control dissolved contaminants and microorganisms in rainwater. This system is a continuous-flow column packed with functional materials (Figure 6). The packing material comprises granular or powdered activated carbon doped with fine particles of iron oxide or zerovalent iron-copper bimetal (denoted as $\mathrm{nFe}-\mathrm{Cu}$ ). 
The porous activated carbon provides a high surface area with active sites on which heavy metals and organic substances effectively adsorb. nFe-Cu doped on activated carbon is a new biocide capable of inactivating both bacteria and viruses.

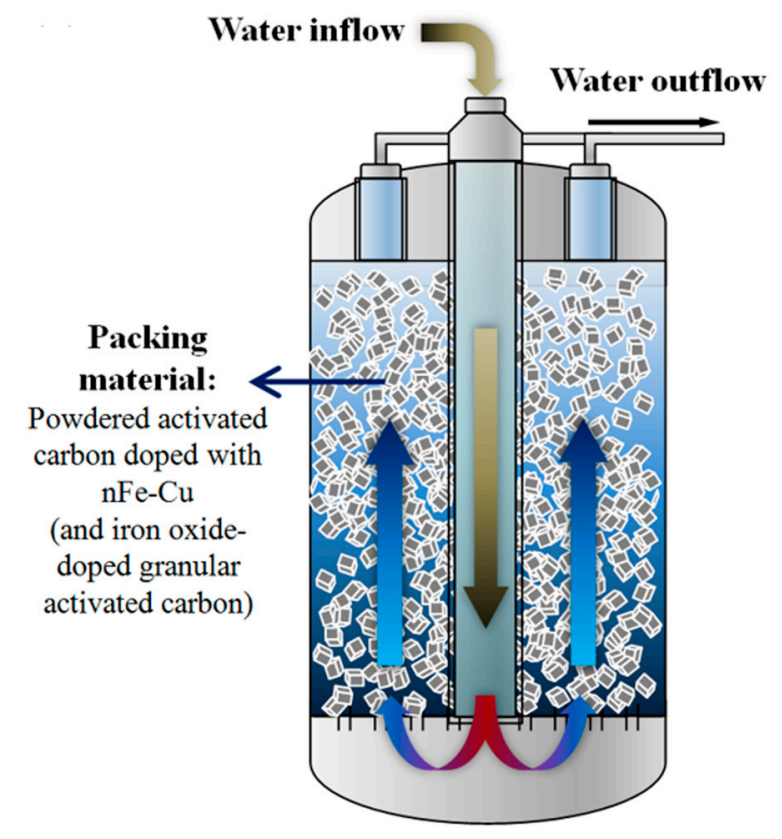

Figure 6. Schematic of integrated adsorption-disinfection system.

\section{Results}

\subsection{Beevi Toilet}

There are three types of Beevi toilet in the pavilion; the first is a commercialized unit with which we can convert feces into compost in approximately one week, the second is a designed and fabricated unit that can produce powder out of fresh feces in about $30 \mathrm{~min}$ to $1 \mathrm{~h}$, and the last is not intended as a toilet but as an exhibition of a model design and sitting experience. We opened our restroom to the public, available for viewing with a reservation, so that visitors can experience and obtain an FSM currency called Ggool (Korean for "honey") in exchange for their participation through either a developed smartphone application or payment with paper money.

\subsection{Biogas Production}

The co-digestion runs (at three different mixing ratios between feces and food waste) and the mono-digestion runs treating feces or food waste all showed similar $\mathrm{CH}_{4}$ yields $(0.404-0.434 \mathrm{~L} / \mathrm{g}$ volatile solids fed $\left(\mathrm{VS}_{\text {fed }}\right)$, Figure 7$)$. These results suggest that feces has promising potential as a feedstock for biogas production. Although, in contrast to a previous study [12], a synergetic effect was not shown in the co-digestion runs, it was demonstrated that feces and food waste can be effectively co-digested without antagonistic effect. Two identical continuously-stirred tank reactors with a working volume of $15 \mathrm{~L}$ are being operated in Sa-Wol-Dang to evaluate the efficiency and stability of the co-digestion process in continuous mode. The reactors have been operated with gradual increases in organic loading rate from 1.5 to $2.5 \mathrm{~g} \mathrm{VS} / \mathrm{L} \cdot$ day for more than 100 days after the initiation (Figure 8). Currently, approximately $0.7 \mathrm{~L}$ biogas $/ \mathrm{g} \mathrm{VS}$ fed with $64 \% \mathrm{CH}_{4}$ content $(v / v)$ is stably produced in each reactor. The digester effluent contains large amounts of nitrogen $\left(>2500 \mathrm{mg} \mathrm{NH}_{4}{ }^{+} \mathrm{N} / \mathrm{L}\right)$ and phosphorus (>100 mg $\mathrm{PO}_{4}{ }^{-} \mathrm{P} / \mathrm{L}$ ), which must be further treated prior to discharge. The project team is developing a post-treatment process for nutrient removal using microalgae under non-sterile 
conditions. The microalgal biomass harvested from the process can be used to produce biodiesel or feed the digesters for further energy recovery via biogas.

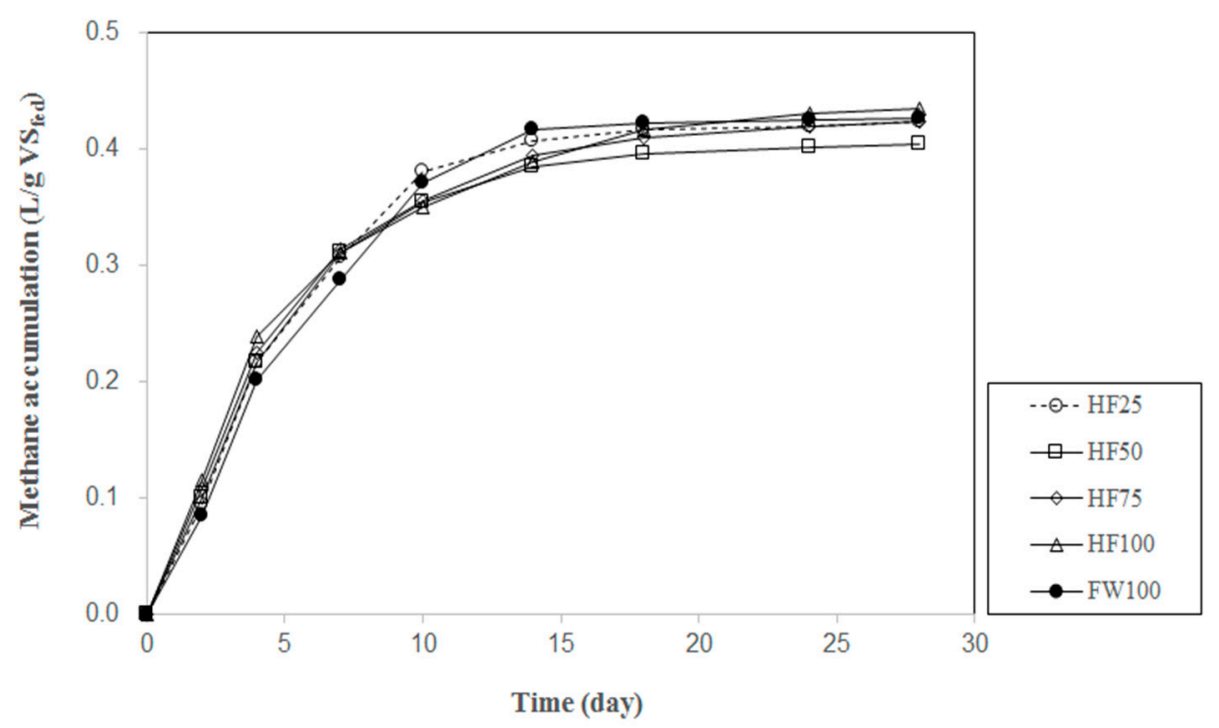

Figure 7. $\mathrm{CH}_{4}$ production profiles in BMP test runs. Runs are labeled with the percentage of human feces (HF). FW100 indicates the mono-digestion run using food waste.

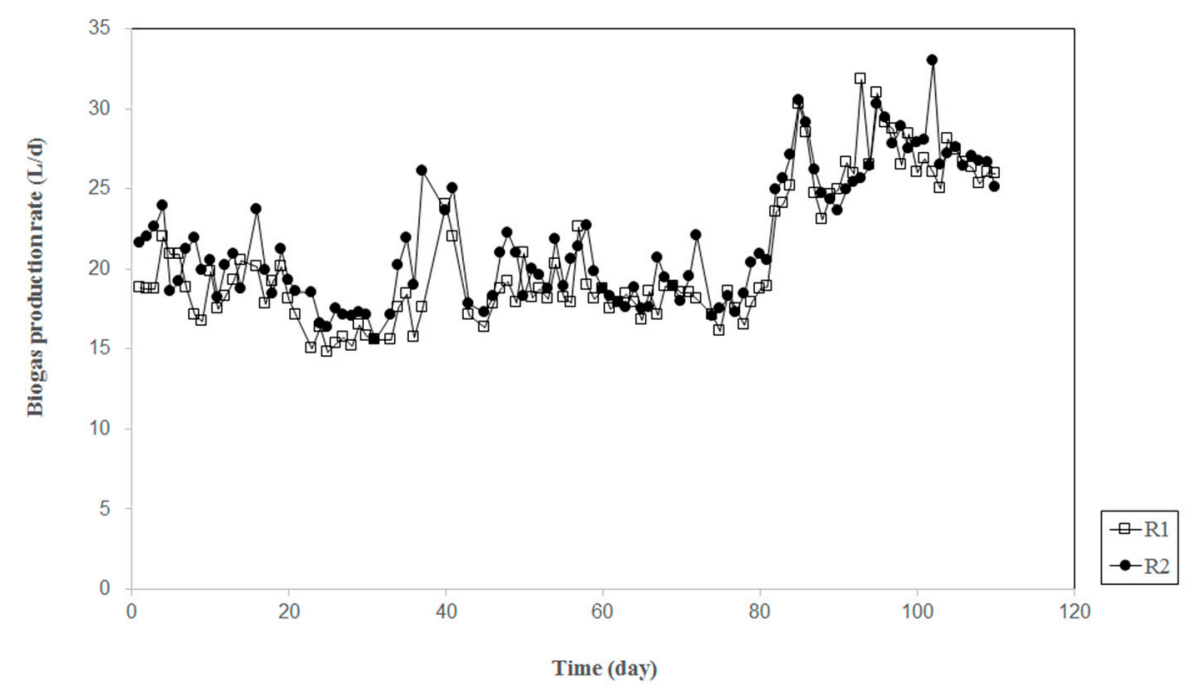

Figure 8. Biogas production in duplicate digesters (R1 and R2) installed in Sa-Wol-Dang.

\section{3. $\mathrm{CO}_{2}$ Capture from Biogas Using Semiclathrates}

The preliminary experiment in the current work showed that only one step of TBAC semiclathrate formation and dissociation produced $75 \% \mathrm{CO}_{2}$ in the semiclathrate phase. With an additional step of semiclathrate formation and dissociation, almost-pure $\mathrm{CO}_{2}$ is expected to be enriched in the semiclathrate phase. However, researchers should further investigate the enhancement of the reaction rate and $\mathrm{CO}_{2}$ selectivity, the exploration of better semiclathrate formers, and the design of a continuous process to develop an energy-efficient semiclathrate-based process for $\mathrm{CO}_{2}$ capture.

\subsection{Purification Using a Membrane Technique}

Figure 9 shows the concentration of $\mathrm{CH}_{4}$ gas under various $\mathrm{pH}$ conditions during membrane operation. Even when using pure water as a solvent for removing $\mathrm{CO}_{2}$, a concentration higher than 
$90 \%$ was achieved within $100 \mathrm{~min}$ at $\mathrm{pH} 8$. The aim of this research was to advance fermentation reaction favorably by removing $\mathrm{CO}_{2}$ in an anaerobic digester. The experiments (Figure 9) showed that the fermentation reaction was easily achieved when a hydrophobic membrane was used.

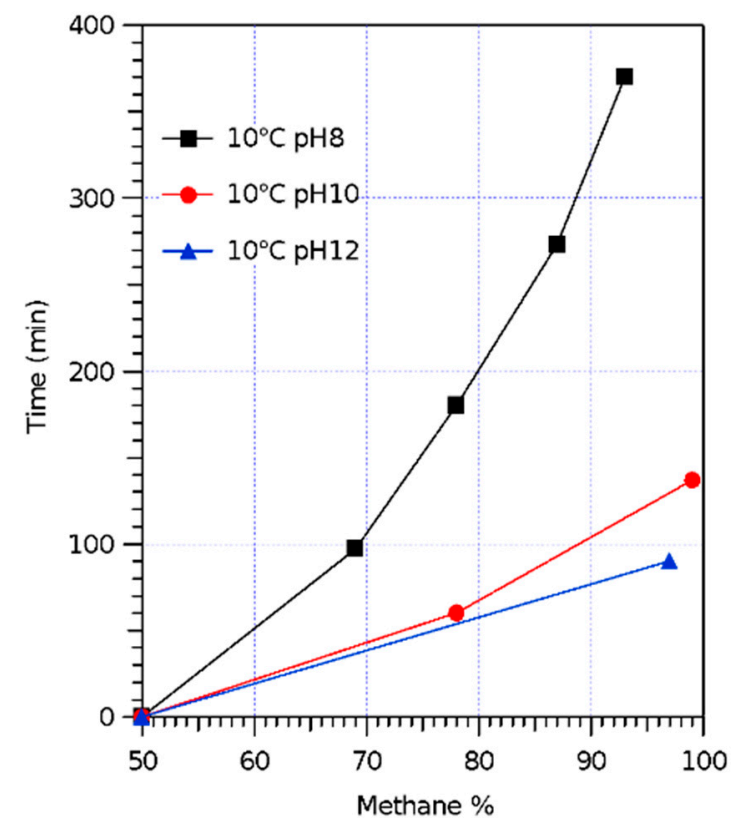

Figure 9. Separation of $\mathrm{CH}_{4}$ from the biogas mixture by a hydrophobic membrane process; initial gas composition was $50 \% \mathrm{CO}_{2}$ and $50 \% \mathrm{CH}_{4}$.

\subsection{Green Roof and Sand Filter System: Rainwater Reduction}

Figure 10 compares the hydrographs and water quality concentrations of roofs and the green roof of Sa-Wol-Dang; the figures apply to the concentrations achieved on 3 August 2016. The comparison showed that surface runoff significantly decreased with the implementation of the green roof. This finding demonstrates that a green roof can contribute to reducing flooding events and pollutant loading into a receiving water body. Effluent from green roofs can be characterized by high phosphate and total phosphorus concentrations. Aitkenhead-Peterson et al. mentioned that phosphorus can be released from the soil layer in a green roof. However, the concentrations of $\mathrm{NH}_{4}+$ and $\mathrm{NO}_{3}-$ decrease when a green roof system is adopted [13].

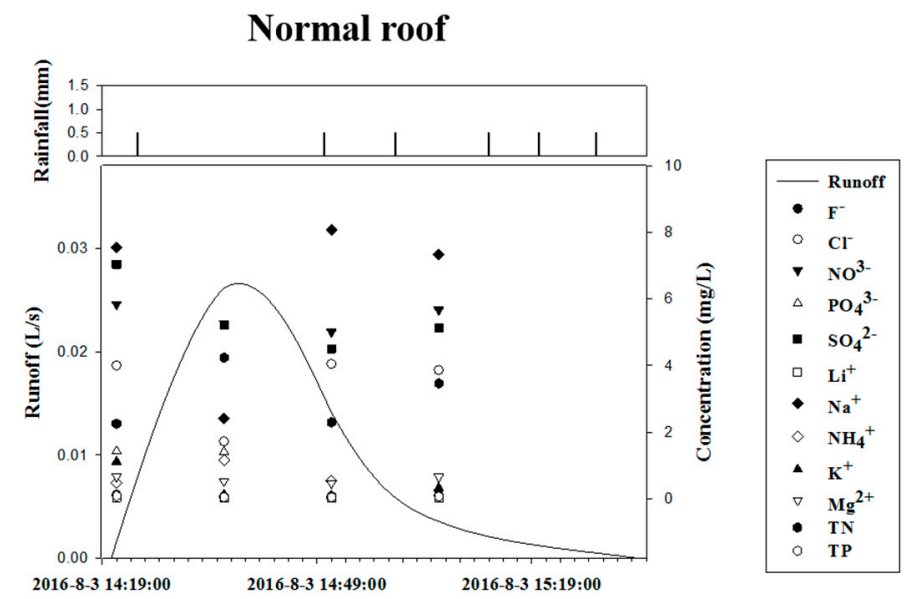

Figure 10. Cont. 


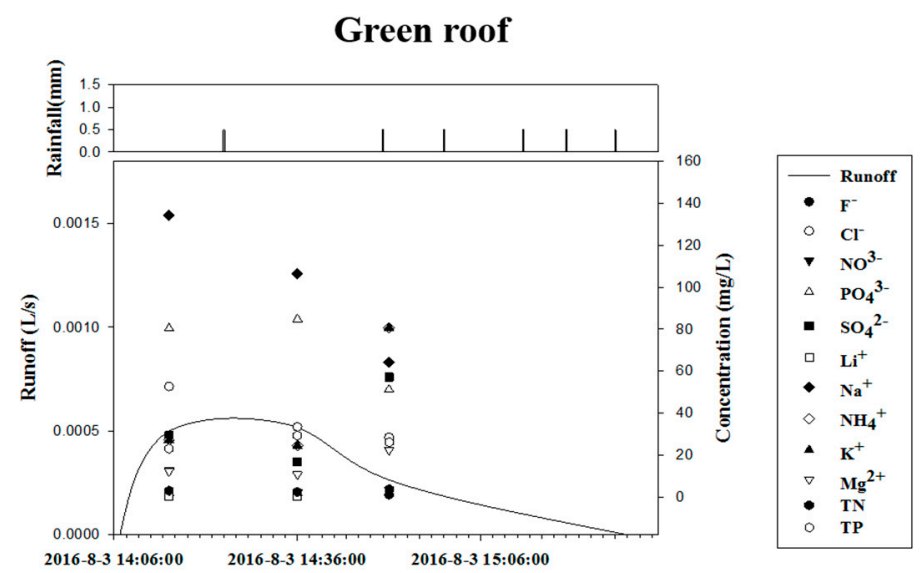

Figure 10. Runoff volumes and water quality from normal and green roofs.

\subsection{Integrated Adsorption-Disinfection System for Rainwater Treatment}

Previous studies on microbial inactivation using iron and copper compounds suggested that the biocidal activity of $\mathrm{nFe}-\mathrm{Cu}$ results from multiple antimicrobial actions, including oxidative stress by in situ-generated reactive oxidants and the cytotoxicity of cuprous species [14-16]. nFe-Cu not only prevents microbial growth on the surface of activated carbon but also inactivates microorganisms in water inflow. Therefore, the hybrid material of activated carbon and $\mathrm{nFe}-\mathrm{Cu}$ plays dual roles as adsorbent and disinfectant. Preliminary data showed that the developed integrated adsorption-disinfection system effectively removed arsenic (a heavy metal) and Escherichia coli and MS2 coliphage (surrogates for bacteria and viruses, respectively) (Figure 11).

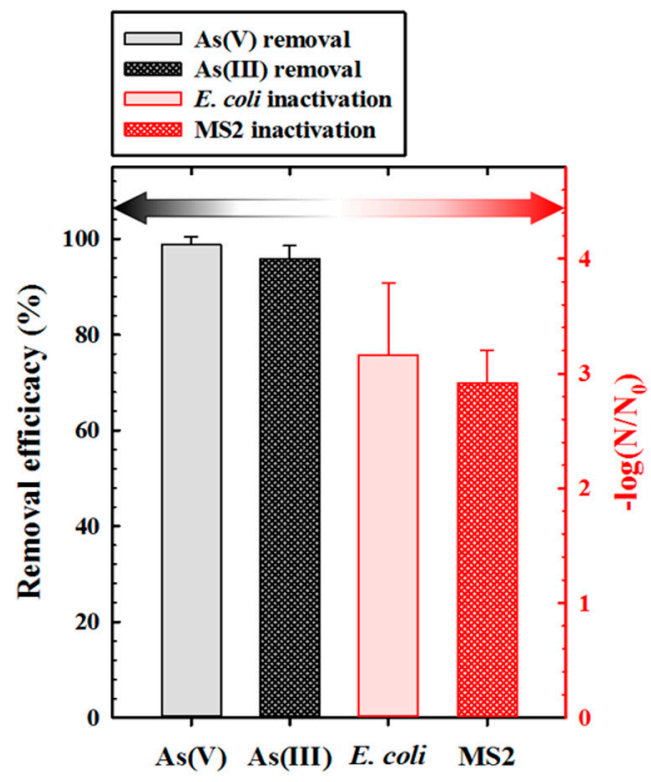

Figure 11. Preliminary data on arsenic removal and microbial inactivation using the packing material and the developed system. Experimental conditions for arsenic removal: $[\mathrm{As}(\mathrm{V})]_{0}=[\mathrm{As}(\mathrm{III})]_{0}=2 \mathrm{mg} / \mathrm{L}$, $\mathrm{pH}=7$, contact time $=6 \mathrm{~h}$, batch-type operation, material = iron oxide-doped granular activated carbon, $[\text { Material }]_{0}=1 \mathrm{~g} / \mathrm{L}$. Experimental conditions for microbial inactivation: $[\text { E. coli }]_{0}=[\mathrm{MS} 2]_{0}=10^{6} \mathrm{CFU}$ or $\mathrm{PFU} / \mathrm{mL}, \mathrm{pH}=7$, retention time $<1 \mathrm{~min}$, continuous-flow operation, material = powdered activated carbon doped with nFe-Cu. 


\section{Design and Art}

Design and art can ease interaction between the general public and scientists because these serve as a means of visualizing an ambiguous theory and concretizing it into an understandable image. Our attempts reflect the considerable possibility that design and art can create products that are more human-centered, comfortable, and convenient. These products then serve liaison-like purposes. That is, the divergent nature of art earns it the recognition as an effective means of facilitating cognitive flexibility and creative imagination. This nature enables art to act as a central site from which diverse paths of thinking can grow in the context of interdisciplinary studies. At Science Walden-an interdisciplinary research project that envisions a world yet to come-this potential of art is valued and expected to enable researchers to move beyond conventional scientific practice and toward many other possible alternatives $[17,18]$.

\subsection{Media Art: Citizen-Friendly Presentation by Info-Blind Technology}

To clearly communicate the activities of our research center and help people easily understand how these activities proceed, an Info-Blind structure with LED lights is used with media art. The specific functions of the Info-Blind are as follows:

(1) Figure 12. The Info-Blind functions as a shading material. Its LED lights are set horizontally on each wing so that it can express the media art connected to the computer in the research center. People can see the media art outside the building through the center's wall, which is semi-transparent.

(2) The biogas that the lab produces every day is visualized as a tree on the blinds, thereby enabling people who pass by the center at night to recognize how much output is produced on a given day. This is an attempt at motivating interaction between the public and the lab's engineers. Without this visualization, the public would be unaware of what is going on in the lab. Ultimately, this media art connects and indirectly communicates with the public as an intermediary by attracting interest.

(3) The logos intended to express the characteristics of each lab involved in the project are presented on the architecture. This is an endeavor at easily communicating to the public what kind of engineering departments have been collaborating in the project and how they are harmonized. People have commented that the entire structure resembles an art museum that offers exhibitions of content to the public.

(4) Figure 13. Community engagement and interpretation as an experimental data collection was used. The authors invited community kindergarten students and explained about what this pavilion is and let them draw anything they learned to see their interpretation. They then admirably drew energy symbols, poo-poo shapes, and toilet images. Their interpretation leads to our results that art is an easy communication tool to understand each other.
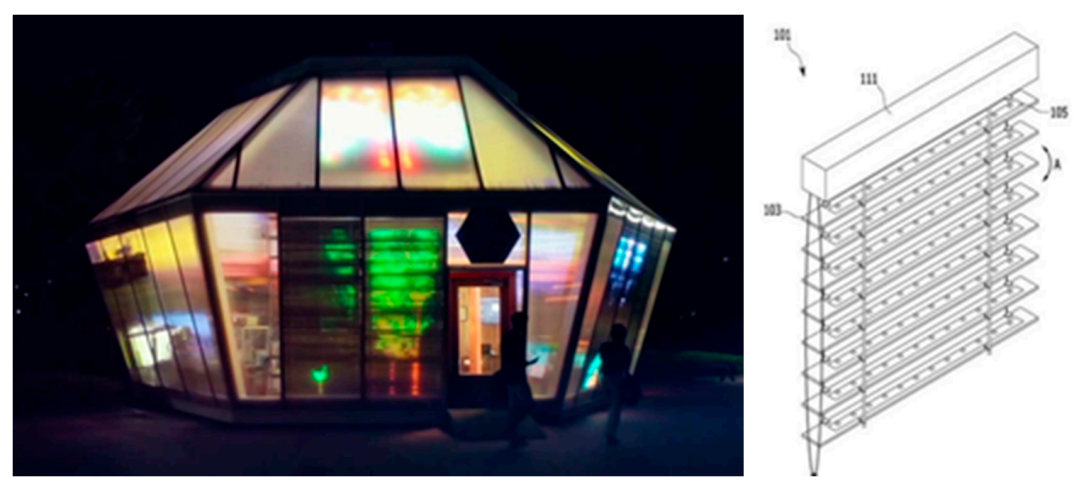

Figure 12. Nighttime media art reflected status and Info-Blind with LED lights attached. 


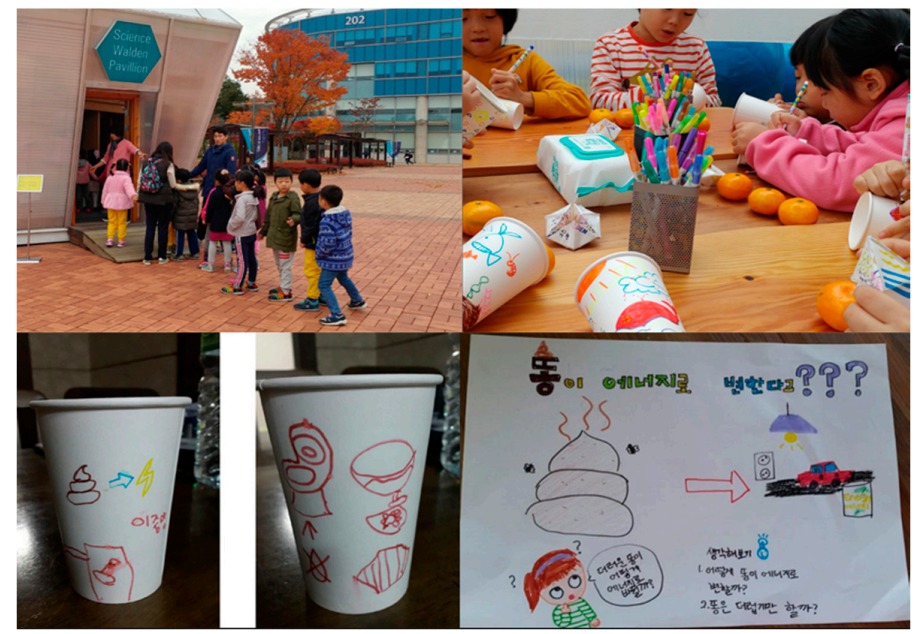

Figure 13. Community engagement and interpretation.

\subsection{Futuristic Toilet Design: User-Centered Approach for Better Convergence}

The aim of designing a futuristic waterless toilet (the Beevi toilet) was not only to raise community awareness of water scarcity but also to save water in South Korea. The toilet features a radical technology-push nature that examines the effectiveness of eliminating phosphorus from the fuzzy front end stage of new product development [19]. An important consideration, however, is that designing a product that is meaningful to users requires an understanding of user experience and perception, as well as how people make sense of things [20]. A thorough understanding of target users and their needs is necessary for success. We, therefore, explored how people as future users in the community perceive water scarcity and the waterless toilets. This is a reflective problem-solving approach [21] to designing a prototype, which can be a solution, an evaluation tool, or a vehicle for team collaboration [22]. The packaged experience thus defines the characteristics of a product, service, or brand [23] and provides economic value as a planned journey with multiple touch points [24].

To investigate users' perceptions and understanding of water scarcity and the waterless prototype, we conducted focus group interviews with 54 participants ( 15 females and 39 males). The participants were asked about (1) their awareness of water scarcity in the country; (2) their previous experience of attempting to save water; (3) how they would be motivated to conserve water; (4) their perception of a waterless toilet; and (5) their dream toilet. The thematic analysis revealed three thematic categories: (1) disbelief about water scarcity; (2) incentives for saving water, such as receiving economic benefits or improving health through the use of the Beevi toilet; and (3) the necessity of cleaner and more sanitary experiences than those offered by current toilets. The results of the interviews indicated that although people have heard of the water scarcity problem, they have not attempted to conserve water given the ease and convenience with which they can access water sources. People want improved experiences from current toilets. This design activity exposed new issues and information needs as the work progressed [24].

We triangulated research methods for designing an alpha prototype on the basis of the interviews and three case studies on experiential civic engagement, in which actual and visual designs were provided and seven expert interviews in the fields of design policy and service design were conducted [25]. These were thematically analyzed, and two themes emerged: (1) readability and (2) vivid color for nudging. The results indicated that in achieving improved civic engagement, a useful approach is to capture people's interest through eye-catching forms of design, vivid colors, or unexpected shapes. Correspondingly, we designed an alpha prototype that deviates from the design of currently available toilets (Figure 14). The prototype is displayed at the Science Walden Pavilion, where people can visit and experience sitting on this futuristic and unconventional toilet. The toilet also enables a sitting posture that differs from that offered by regular toilets. As a person 
sits on the prototype toilet, the position of the seat gradually drops to a level lower than the initial seat height, thus enabling a person's leg to be slightly raised. This allows for a healthier posture when expelling excrement. The prototype offers possibilities for further research in terms of integrating FSM (as economic value) and universal toilet sitting postures for healthier expelling of excrement. The prototype was designed in accordance with a user-centered approach as a sociable design, which "is for the benefit of the people who use it, taking into account their true needs and wants" [26].

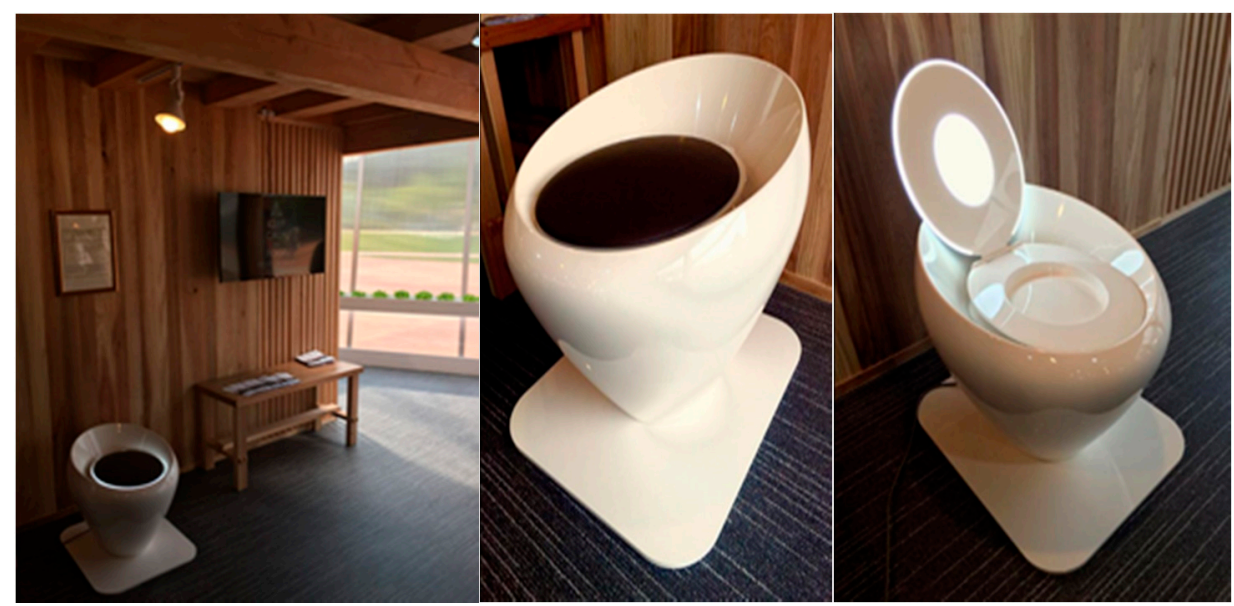

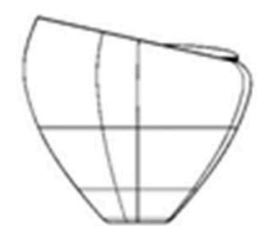

1. UV Iights sterilize the seat and bwol during combustion.
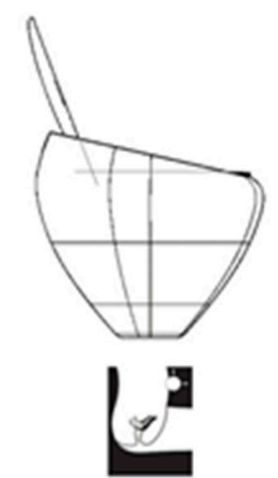

2. The lid automatically opens when it detects a user.
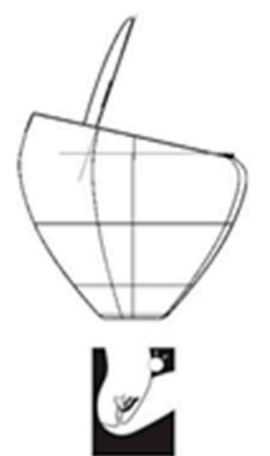

3. The seat can adjust to the angle that is most comfortable to dofocate with the touch of a button.

Figure 14. Alpha prototype of the futuristic Beevi toilet displayed at the Science Walden Pavilion.

The characteristics of the prototype are listed below.

(1) UV lights were installed on the toilet cover not only for a hygienic look but also for actual sanitation of the seating component. As people occupy the seat, the design provides them a sense of freshness.

(2) The lid automatically opens when it detects a user. The unoccupied seat remains at a horizontal angle, similar to a typical toilet, but when people sit on it, the angle is adjusted to a level that most effectively facilitates comfort and bowel movement through the straightening of the rectum. After use, the seat spring gently nudges the user upward, so people, including the elderly, can easily stand up. The toilet features an ergonomic design that helps people avoid constipation and eventually improve their health conditions.

(3) Form-wise, the waterless toilet does not have a cylindrical shape for water centrifugal force. Instead, it has a catenary shape that resembles a wine glass or a vanity table. The shape accords with the idea of a toilette, a French word that roughly translates to "furniture that one can make oneself up". The white color scheme gives people the sense of increased cleanliness. 


\subsection{Futuristic Community Design: Hexagon}

The proposed environmental technology and products that are characterized by the convergence of art and technology are intended to be systematically integrated and materialized in the community design. In designing Science Walden, we first presumed a small neighborhood composed of 50 households and identified the key functionality and spatial usage within the community. We then developed a Science Walden community concept that is flexible and easily expandable in the future.

The design involved four steps. First, we classified the socio-demographic features of potential residents into multiple classes: elderly couple households, working couple with children households, and single-person households. The living scenarios of each family were then depicted in detail. We presumed that the living patterns in Science Walden are fundamentally different from those in ordinary communities. Living schedules in our community include community building activities, Science Walden education, community farming, and consuming products with FSM. Second, we identified commonly-observed behavioral patterns across diverse social classes on the basis of the living scenarios and connected these behaviors to specific spatial functions. For instance, production occurs at the biocenter that generates bio-energy, monetary activities take place at a golden bank where inhabitants exchange feces for FSM, and local food production happens in a community farm. Third, a system for the Science Walden community was developed. The built environment and functionality of Science Walden design resembles the town of Arcosanti in Arizona, US. Arcosanti, designed by Paolo Soleri, emphasize the principles of social integration, self-containment of habitat and food and energy production [27]. The innovative feature of the Science Walden community is the introduction of FSM. The community system incorporates various key functions of the community, the circulation of FSM, local exchange, and community education. FSM becomes the key element that connects various activities in the integrated system. Figure 15 illustrates the proposed system of the Science Walden community. Finally, we developed a prototype Science Walden design, which has several features. To apply the design concept in various city contexts, the shape of an envisioned community should be flexible. The proposed community is not a neighborhood with fixed forms and functions but allows metabolic change and expansion. These principles share common ground with the metabolism movement in architecture, which considers society a living and mutable entity and pursues the transformation of society through technology and urban design [28]. In terms of geometry, the proposed prototype design is of a hexagonal plan. The hexagon plan was introduced to an alternative to the rectangular grid for residential subdivisions and buildings [28]. Each unit of the hexagon has a unique functionality of space, and spaces are arranged next to one another in patterns that are appropriate for creating different Science Walden communities. The size of the hexagonal module and the manner by which modules are combined and converted is easy, thus corresponding with the local context of a given neighborhood.

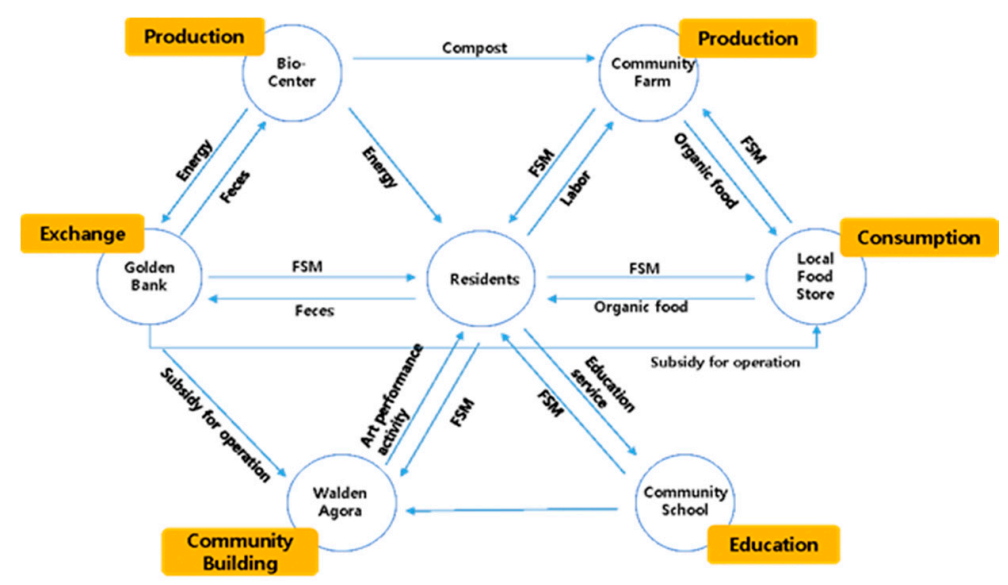

Figure 15. Proposed system of the Science Walden community. 


\section{Conclusions: Convergence of Science and Art}

Throughout the sequential process on energy production and water purification, we demonstrated that our community can be constructed in an environmentally-friendly manner by reducing human waste, producing energy, and purifying rainwater. However, deeper research on the sequential processes should be incorporated to achieve high efficiency and to make water more valuable. With respect to the biogas production, we need to develop a more reliable post-treatment process to remove nutrients. Additionally, our climate can be characterized by monsoons, where precipitation mostly concentrates in the summer season. This implies that we need to propose the optimal size of the green roof and the integrated adsorption-disinfection system.

We believe that we need to develop a system wherein scientists and artists can freely communicate with each other. The system can be actualized in the form of a project in which all kinds of communicative acts, behaviors, and events occur; Science Walden may serve as a representative example of such a system. The system comprises not of participating persons but of communication activities. It is, therefore, unfixed; it is a very flexible system given that it varies with the incorporation of diverse elements, whose boundaries are demarcated differently by diverse times and spaces. In the project, we communicate with one another by sharing information that is based on our own experiences. A project is an open space where we can collaborate, practice and, most importantly, cultivate ourselves. We need a medium of communication, such as a language, especially in this project, wherein scientists and artists collaborate. We share the common goals of the project and discuss the selection of media for effective communication; letters are an example, but images, sounds, smells, and other sense-provoking items may also be considered. An observation of an object gives us an impression, a representation, a sensation, and an image that will eventually form knowledge of concepts or ideas. Transfer of knowledge occurs through media, and such formation and transfer are the goals for which scientists and artists are responsible. Of course, we can create knowledge of concepts by using language and many other types of media. Let us take the concept of FSM as an example: artists can help scientists understand this concept and represent it through scientific experiments, such as bio-energy production of feces. As we discussed, artists share some parts of their methodology in establishing the concept with scientists. Artists are adept at treating non-textual knowledge, which is composed of non-propositional concepts. We can collect both textual and non-textual knowledge in our faculty of concepts, titling it as the non-textual library of FSM. Instead of publishing numerous papers in journals, like most scientists do, we can contribute to our community in a different manner. To achieve this goal, we should first understand the language of other fields. For instance, science and art can converge as scientists and artists learn each other's modes of presenting ideas. They should meet to communicate in their own language. In so doing, they naturally expose themselves to each other, understand their difference in terms of modes of communication, and eventually determine how to reduce the gap between them. As a next step, a project that elicits the interest of scientists and artists should be launched. Such a project will ease encounters between scientists and artists. A project is not a pursuit exclusive to privileged experts; rather, all people can participate in an endeavor and, in the process, become qualified experts as they engage in project-related practices. Participants do not perform, but use the project itself to study. After this, artists and scientists should try to find common ground in the design of a product for the project. Upon finding appropriate materials, they can proceed to the design of next steps, which include the selection of meaningful activities. Finally, scientists and artists must share visions and goals. Only then can we find a way to transform what is currently unimaginable and intangible into a realizable and perceptible outcome.

Acknowledgments: This work was supported by the National Research Foundation of Korea (NRF) Grant funded by the Korean Government (MSIP) (No. NRF-2015R1A5A7037825).

Author Contributions: Kyung Hwa Cho and Hyun-Kyung Lee conceived and designed the experiments; Changsoo Lee and Jaeweon Cho and Huiyuhl Yi performed the experiments; Yongwon Seo and Gi-Hyoug Cho analyzed the data; Young-Nam Kwon and Changha Lee and Kyong-Mi Paek contributed reagents/materials / analysis tools; Kyung Hwa Cho and Hyun-Kyung Lee wrote the paper. 
Conflicts of Interest: The authors declare no conflict of interest.

\section{References}

1. Thoreau, H.D. Walden; or Life in the Woods; Ticknor and Fields: Boston, MA, USA, 1854.

2. Skinner, B.F. Walden Two; Hackett Publishing Company: Indianapolis, IN, USA, 1948.

3. Ahring, B.K. Biomethanation I; Springer: New York, NY, USA, 2003.

4. Fowler, D.; Loebenstein, W.; Pall, D.; Kraus, C.A. Some unusual hydrates of quaternary ammonium salts. J. Am. Chem. Soc. 1940, 62, 1140-1142. [CrossRef]

5. Aladko, L.; Dyadin, Y.A.; Rodionova, T.; Terekhova, I. Clathrate hydrates of tetrabutylammonium and tetraisoamylammonium halides. J. Struct. Chem. 2002, 43, 990-994. [CrossRef]

6. Kim, S.; Seo, Y. Semiclathrate-based $\mathrm{CO}_{2}$ capture from flue gas mixtures: An experimental approach with thermodynamic and Raman spectroscopic analyses. Appl. Energy 2015, 154, 987-994. [CrossRef]

7. Kim, S.; Kang, S.P.; Seo, Y. Semiclathrate-based $\mathrm{CO}_{2}$ capture from flue gas in the presence of tetra-n-butyl ammonium chloride (TBAC). Chem. Eng. J. 2015, 276, 205-212. [CrossRef]

8. Baek, S.S.; Choi, D.H.; Jung, J.W.; Lee, H.; Yoon, K.S.; Cho, K.H. Optimizing low impact development (LID) for stormwater runoff treatment in urban area, Korea: Experimental and modeling approach. Water Res. 2015, 86, 122-131. [CrossRef] [PubMed]

9. Baek, S.; Choi, D.; Jung, J.; Yoon, K.; Cho, K.H. Evaluation of hydrology and runoff BMP model in SUSTAIN on commercial area and public park in South Korea. Desalin. Water Treat. 2015, 55, 347-359. [CrossRef]

10. Pandey, D.N.; Gupta, A.K.; Anderson, D.M. Rainwater harvesting as an adaptation to climate change. Curr. Sci. 2003, 85, 46-59.

11. Helmreich, B.; Horn, H. Opportunities in rainwater harvesting. Desalination 2009, 248, 118-124. [CrossRef]

12. Rajagopal, R.; Lim, J.W.; Mao, Y.; Chen, C.-L.; Wang, J.-Y. Anaerobic co-digestion of source segregated brown water (feces-without-urine) and food waste: For Singapore context. Sci. Total Environ. 2013, 443, 877-886. [CrossRef] [PubMed]

13. Aitkenhead-Peterson, J.A.; Dvorak, B.D.; Volder, A.; Stanley, N.C. Chemistry of growth medium and leachate from green roof systems in south-central Texas. Urban Ecosyst. 2011, 14, 17-33. [CrossRef]

14. Lee, C.; Kim, J.Y.; Lee, W.I.; Nelson, K.L.; Yoon, J.; Sedlak, D.L. Bactericidal effect of zero-valent iron nanoparticles on E. coli. Environ. Sci. Technol. 2008, 42, 4927-4933. [CrossRef] [PubMed]

15. Park, H.-J.; Nguyen, T.T.M.; Yoon, J.; Lee, C. Role of reactive oxygen species in Escherichia coli inactivation by cupric ion. Environ. Sci. Technol. 2012, 46, 11299-11304. [CrossRef] [PubMed]

16. Nguyen, T.M.; Park, H.-J.; Kim, J.Y.; Kim, H.-E.; Lee, H.; Yoon, J.; Lee, C. Microbial inactivation by cupric ion in combination with $\mathrm{H}_{2} \mathrm{O}_{2}$ : Role of reactive oxidants. Environ. Sci. Technol. 2013, 47, 13661-13667. [CrossRef] [PubMed]

17. Davis, J. Why Our Schools Need the Arts; Teachers College Press: New York, NY, USA, 2008.

18. Eisner, E. The Arts and the Creation of Mind; Yale University Press: New Haven, CT, USA, 2002.

19. Smith, P.G.; Reinertsen, D.G. Developing Products in Half the Time; Van Nostrand Reinhold: Bel Air, CA, USA, 1991.

20. Krippendorff, K. On the essential contexts of artifacts or on the proposition that design is making sense (of things). Des. Issues 1989, 5, 9-39. [CrossRef]

21. Schön, D. The Reflective Practitioner; Basic Books: New York, NY, USA, 1984.

22. Kelley, T.; Littman, J. The Ten Faces of Innovation; Doubleday: New York, NY, USA, 2005.

23. Press, M.; Cooper, R. Design Experience; Ashgate Publishing Limited: London, UK, 2003.

24. Voss, C.; Zomerdijk, L. Innovation in experiential services-An empirical view. In Innovation in Services; DTI, Ed.; DTI: London, UK, 2007; pp. 97-134.

25. Loch, C.; DeMeyer, A.; Pich, M.T. Managing the Unknown: A New Approach to Managing High Uncertainty and Risk in Projects; John Wiley and Sons: Hoboken, NJ, USA, 2006.

26. Norman, D. Living with Complexity; The MIT Press: Gotham, NY, USA, 2010. 
27. Pernice, R. Metabolism reconsidered its role in the architectural context of the world. J. Asian Arch. Build. Eng. 2004, 3, 357-363. [CrossRef]

28. Ben-Joseph, E.; Gordon, D. Hexagonal planning in theory and practice. J. Urban Des. 2000, 5, $237-265$. [CrossRef]

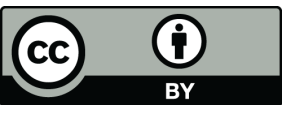

(C) 2016 by the authors; licensee MDPI, Basel, Switzerland. This article is an open access article distributed under the terms and conditions of the Creative Commons Attribution (CC-BY) license (http:/ / creativecommons.org/licenses/by/4.0/). 